\title{
Research on Control Strategy for Three-Phase Four-Wire LCL-Based Active Power Filter
}

\author{
Longfei Li and Xinjian Jiang
}

\begin{abstract}
To improve the high frequency compensation performance, LCL-filter is used instead of L-filter in three-phase four-wire active power filter (APF). In this paper, the characteristic of LCL-filter is discussed. The three-loop control strategy with active damping using capacitor current feedback is introduced. Then the system stability is analyzed by bode and zero-pole diagram, especially considering the time delay of the control system. The results of simulation and experiment prove the effectiveness and stability of the proposed control strategy.
\end{abstract}

Index Terms-Active Power Filter (APF), active damping, delay, lcl-filter, stability.

\section{INTRODUCTION}

As the power quality problem becomes more serious, active power filter (APF) is considered that has better compensation effect in compensating the harmonics and reactive power current since it doesn't depend on the parameters of the grid [1].

Generally, APF is connected to the grid with single L-filter. But it has worse high frequency proformance. LCL-filter has been proposed to replace L-filter because it can suppress the switching harmonics and has better result with lower inductance.

As a third-order resonance system, LCL-filter may cause the system disability. Passive damping is widely used by adding a resistance in series with the capacitor. However, it will cause power consumption and decrease the attenuation ability. Active damping can reduce the power consumption and make the system stable by changing the structure of the controller. Besides, the time delay of control system also has a big influence on the stability. In [2], [3], the filter characteristic of LCL is given but it is used in active power rectifier. [4], [5] have proved that passive and active damping are effective in APF, but it is just for three-phase three-wire APF and the influence of time delay is not put into consideration.

In this paper, a three-phase four-wire APF with LCL-filter is introduced. The system structure and the control strategy with active damping method is proposed and the stability is analyzed, with the consideration of system delay. Finally, simulation and experiment results of a $75 \mathrm{kVA}$ APF are provided to verify the effectiveness and stability of the proposed control strategy.

Manuscript received October 11, 2012; revised November 21, 2012.

Longfei Li and Xinjian Jiang are with the Department of Electrical Engineering, Tsinghua University, Beijing 100084, China (e-mail: lilf11@ mails.tsinghua.edu.cn, jiangxj@ mail.tsinghua.edu.cn).

\section{System Model ANALYZE}

\section{A. APF Principle}

The structure of APF with LCL-filter is shown in Fig. 1, where $L, L_{g}$ and $C_{f}$ form the three-order filter.

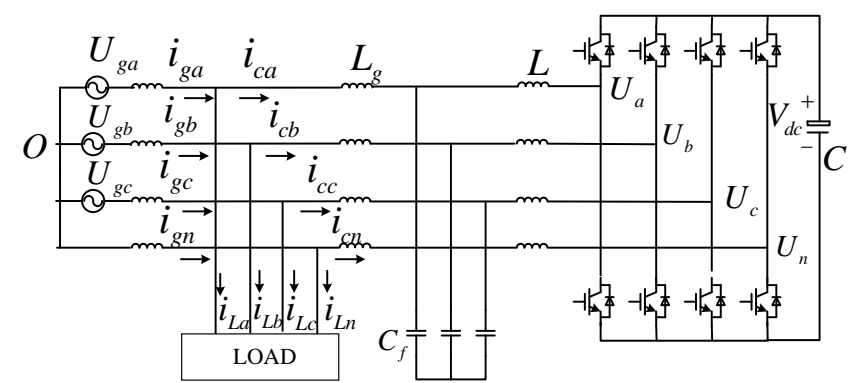

Fig. 1. The structure of APF with LCL-filter

APF detects the harmonic current to generate the reference current and provides the opposite harmonic current into the grid so that the grid current is sinusoidal. Meanwhile, it can also compensate the zero-sequence current by the control of the fourth bridge arm. The output filter should suppress the current ripple and satisfy the demand of current compensation. LCL-filter is adopted for its better performance.

\section{B. Model and Characteristic Analysis of LCL-Filter}

The single-phase block diagram of LCL-filter is shown in Fig. 2.Where $u_{i}$ and $i_{i}$ are the output voltage and current of VSC and $u_{g}$ and $i_{g}$ are the voltage and current of power grid.

According to Fig. 2, the transfer function of LCL-filter can be written as

$$
G(s)=\frac{i_{g}(s)}{u_{i}(s)}=\frac{1}{L L_{g} C_{f} s^{3}+\left(L+L_{g}\right) s}
$$

Compared with the L-filter, LCL-filter is a three-order system and the bode diagram of both are shown in Fig.3

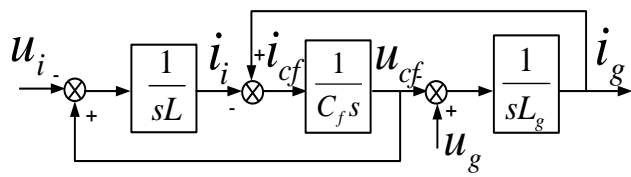

Fig. 2. Single-phase block diagram of LCL-filter

At high frequency, the attenuation rate of LCL-filter is $60 \mathrm{~dB} /$ decade, which is much better than L-filter. At low frequency, they are almost the same. So the LCL-filter has better compensation performance. However, there is a resonance peak in LCL-filter, which may cause disability in the system. 


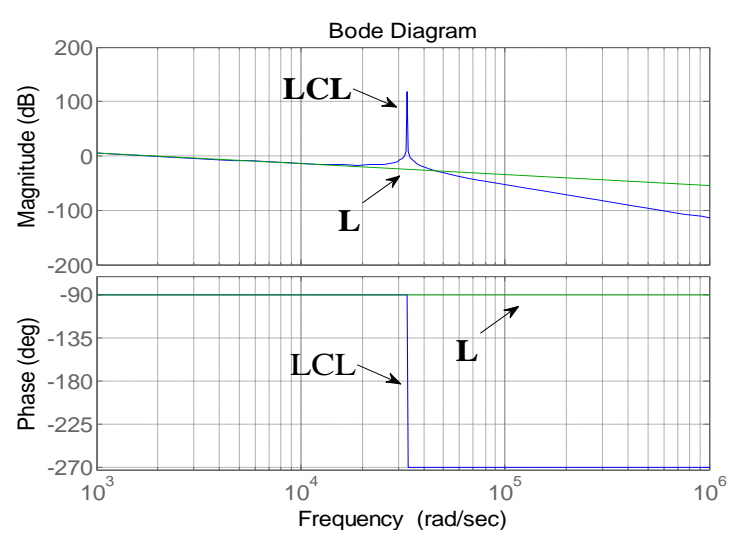

Fig. 3. Bode diagram of $\mathrm{L}$ and LCL-filter

\section{System Parameters}

To select the parameter of LCL-filter, three factors should be taken into consideration: the current ripple, the reactive power generated by capacitor and the suppress ability of high frequency current [6].

The parameter of the system is shown in Table I.

TABLE I: PARAMETER OF APF

\begin{tabular}{cccccc}
\hline \hline $\begin{array}{c}\text { Grid } \\
\text { voltage }(\mathrm{V})\end{array}$ & $\begin{array}{c}\text { Switch } \\
\text { Frequency }(\mathrm{Hz})\end{array}$ & $\mathrm{U}_{\mathrm{dc}}(\mathrm{V})$ & $\mathrm{Lg}_{\mathrm{g}}(\mathrm{mH})$ & $\mathrm{L}(\mathrm{mH})$ & $\mathrm{C}_{\mathrm{f}}(\mathrm{uF})$ \\
\hline 380 & $10 \mathrm{k}$ & 700 & 0.05 & 0.5 & 20 \\
\hline \hline
\end{tabular}

\section{CONTROL STRATEGY AND SYSTEM STABILITY}

\section{A. System Control Structure}

The control block diagram is shown in Fig.4. It consists of three control loops: the dc voltage loop, the compensation current loop and the capacitor current feed-back loop. The output current tracks the reference current and the capacitor current is fed back to keep the system stable.

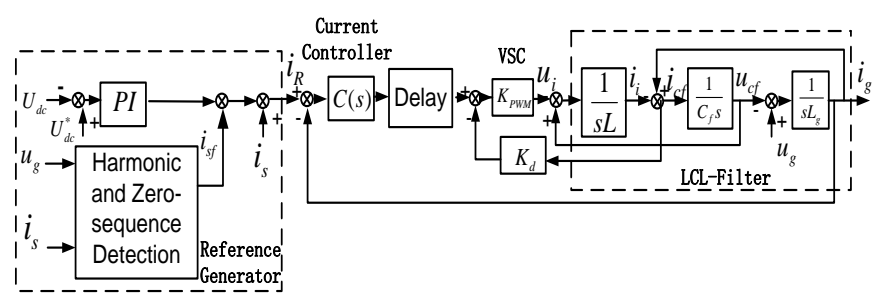

Fig. 4. Block diagram of control system

The selective harmonic detect method with zero phase sequence current is adopted, as shown in [7]. It is based on the instantaneous reactive power theory and detects both three-phase harmonic current and zero phase sequence current so as to make the three-phase current sinusoidal and balance.

The dc-bus voltage is regulated by a PI regulator to compensate the loss of the VSC and maintain the dc voltage. The output of PI regulator is added to the active power part to form the total reference current.

\section{B. Stability Analysis}

As the dc voltage loop has little influence on the system stability analysis, it can be ignored and only the current loop is considered. The most important part is the stability of
LCL-filter with capacitor current feedback. The inner loop of the control system is shown in Fig.5.

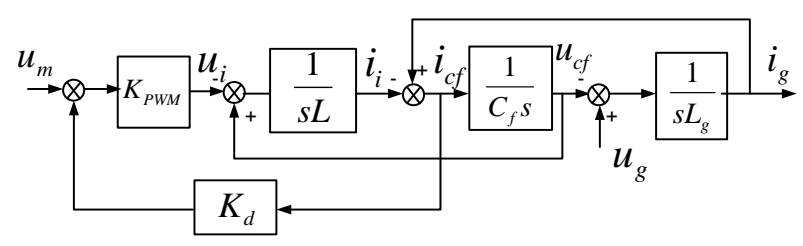

Fig. 5. Inner loop of the control system

Assuming $K_{P W M}=1$, the transfer function of the inner current loop is

$$
G_{a d}(s)=\frac{1}{L L_{g} C_{f} s^{3}+L_{g} C_{f} K_{d} s^{2}+\left(L+L_{g}\right) s}
$$

where $K_{d}$ is the feedback gain of the capacitor current. Considering the close-loop of the current control, the root locus of $K_{d}$ is shown in Fig. 6

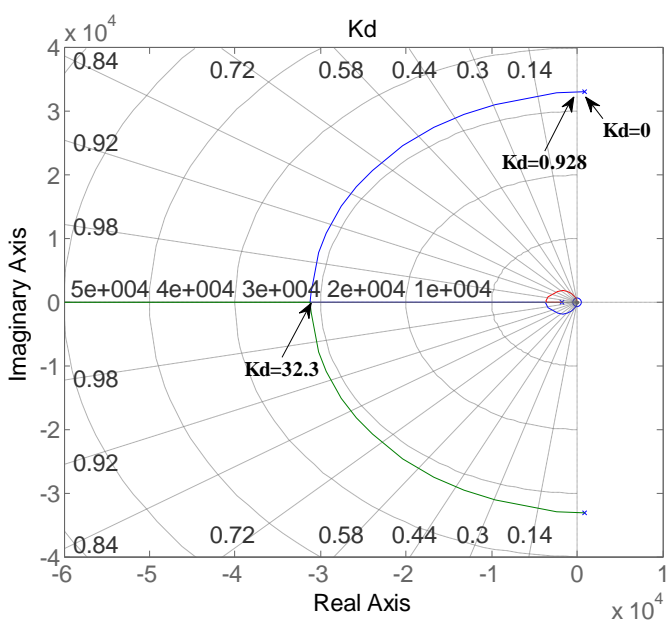

Fig. 6. Root lotus of $K_{d}$

In Fig. 6, the poles of the system lie in the right half when $K_{d}=0$ so that the system is unstable without damping method. The stable range is $K_{d}>0.928$. So the introduce of the capacitor current feedback has the equal effect of the damping resistor but the power loss is much reduced.

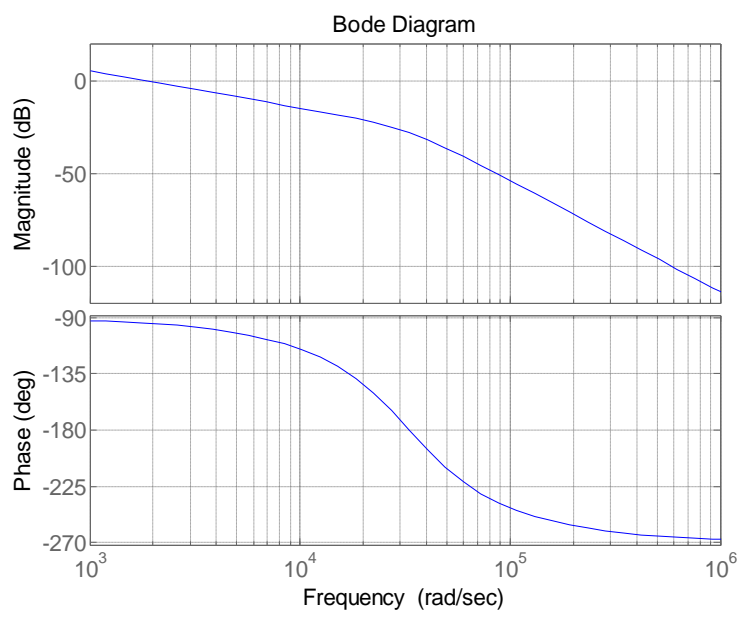

Fig. 7. Bode diagram with active damping

The bode diagram of LCL-filter with active damping is shown in Fig. 7. Compared with Fig. 3, the resonance peak is suppressed obviously and the high frequency suppressing 
ability is still $60 \mathrm{~dB} / \mathrm{decade}$.

In real digital control system, there exists time delay because of the sampling and calculating. The influence of the time delay should also be analyzed because it may change stability or the parameter decision. The pole-zero mapping method in discrete system is used. The control system in Fig. 1 is discretized with zero-order method.

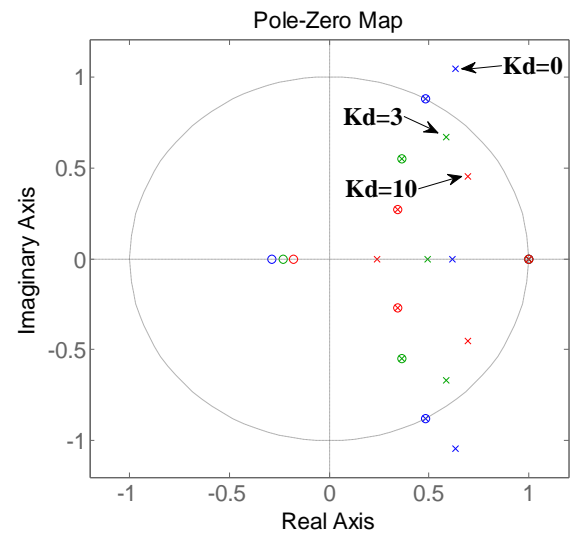

Fig. 8. Pole-zero map with no delay

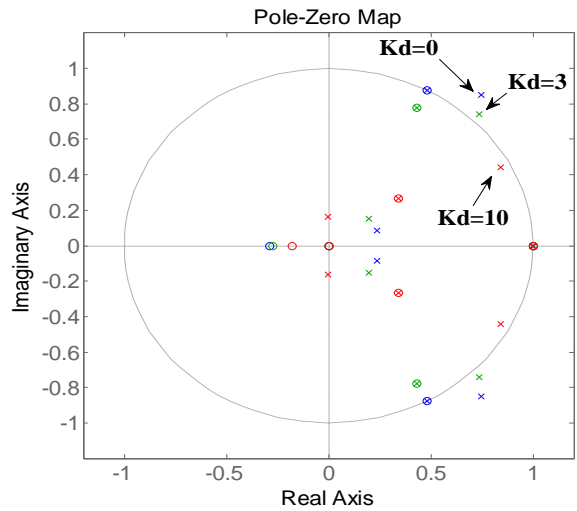

Fig. 9. Pole-zero map with time delay

When no delay is considered, the pole-zero map is shown in Fig. 8. The system is unstable without damping, as discussed above. When active damping is added, the poles come into the unit circle, making the system stable.

The delay in control system will cause phase lag. Take the one control delay into the system, the pole-zero map is shown in Fig. 9. When $K_{d}=3$, the pole comes outside the unit circle, making the system unstable. When $K_{d}=10$, the system is stable but the stable margin much smaller. It can be concluded that when the system has time delay, there still exists stable condition, but it will change the stability of the system under some certain parameter. So the time delay must be put into consideration, and the parameters should be selected again.

\section{Simulation Result}

A three-phase four-wire APF simulation system is constructed as Fig. 1 and the parameters are the same as in TABLE.I

Fig. 11 shows the grid current $\left(i_{\mathrm{S}} / \mathrm{A}\right)$ and zero-sequence current $\left(i_{\text {sn }} / A\right)$ without APF. The THD is $26.64 \%$ and with the unbalance load, the zero-sequence current is very high.

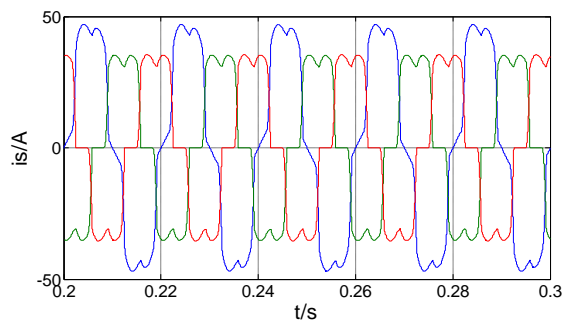

(a) Grid current

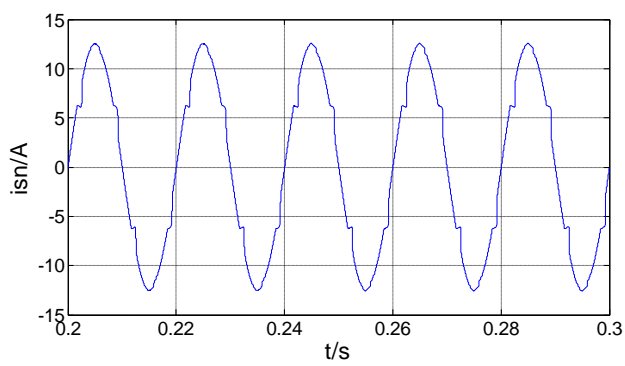

(b) Zero-sequence current

Fig. 11. Grid and zero-sequence current without APF

Fig. 12 and Fig. 13 show the result of L-filter and LCL-filter. Using the L-filter, THD decreases to $8.45 \%$ but switching harmonic is high. When using LCL-filter with active damping, THD becomes $4.64 \%$ and switching harmonic is obviously suppressed. So LCL-filter has better high frequency compensation performance.

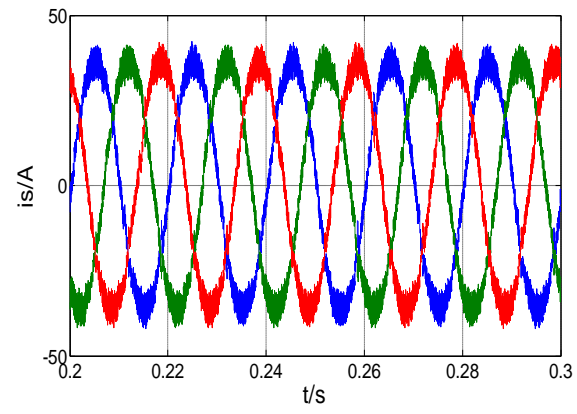

(a) Grid current

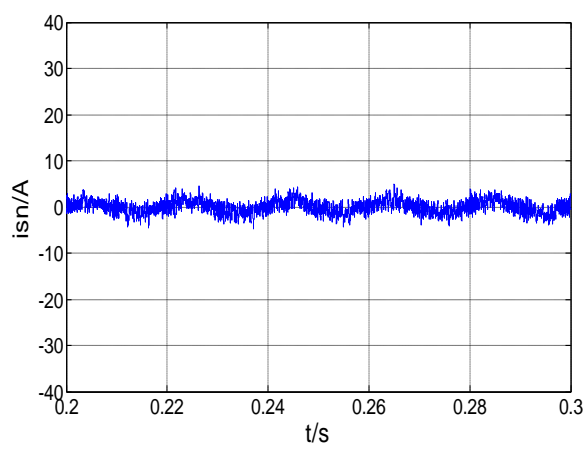

(b) Zero-sequence current

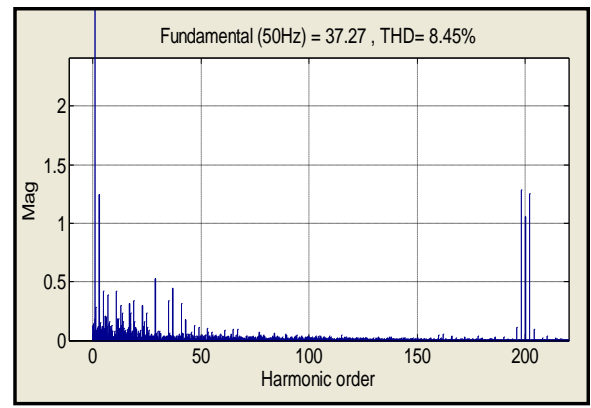

(C) harmonic spectra

Fig. 12 Simulation result with L-filter 


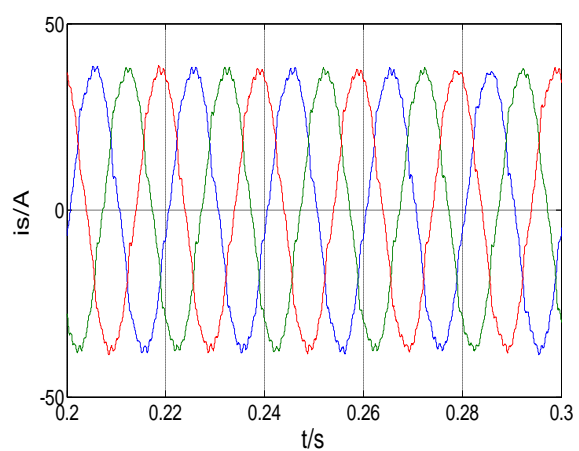

(a) Grid current

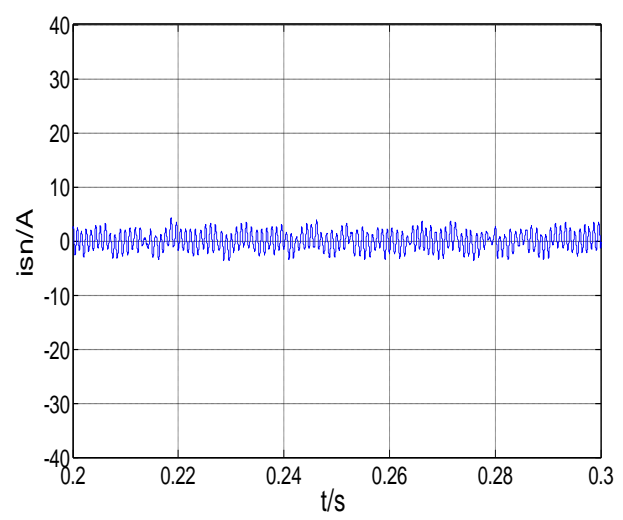

(b) Zero-sequence current

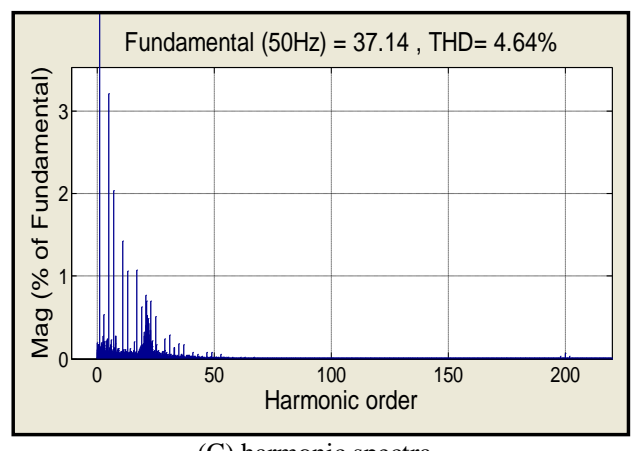

(C) harmonic spectra

Fig. 13. Simulation result with LCL-filter

\section{EXPERIMENT RESULT}

Fig. 14 shows the experiment result under L-filter. The THD of grid current is $6.1 \%$, with lots of high frequency harmonics. Fig.15 shows the experiment result under LCL-filter, where the THD of grid current has been reduced to $5.3 \%$. The three phase currents are balanced and the zero sequence current is very small. It confirms that good performance of harmonic elimination has been achieved by the use of the LCL-filter.

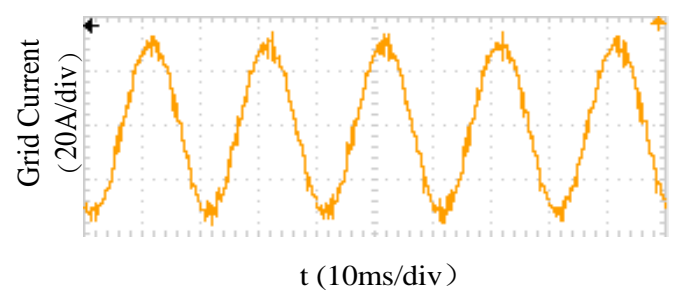

(a) Grid current

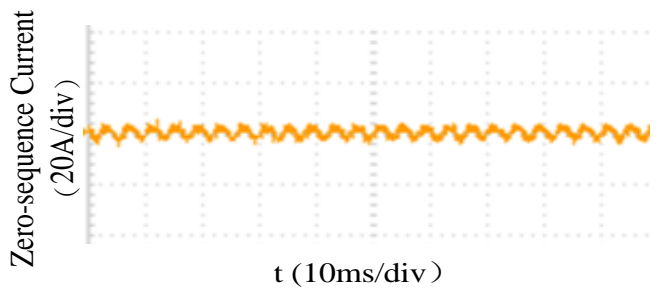

(b) Zero-sequence current

Fig. 14. Experiment results with L-fliter

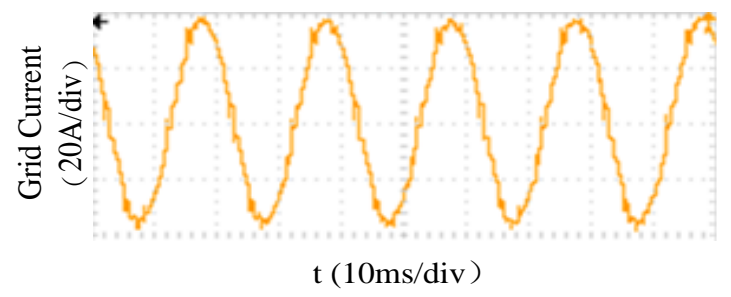

(a) Grid current

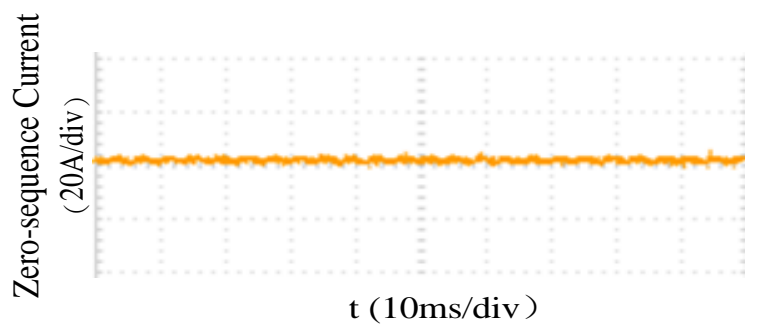

(b) Zero-sequence current

Fig. 15. Experiment results with LCL-fliter

\section{CONCLUSION}

Aiming to improve the compensation performance of the APF, the LCL-filter is used instead of L-filter. The model and the characteristic are analyzed and the control strategy with active damping is introduced. The influence to system stability of capacitor current feedback and control delay are discussed and the existence of delay time may change the system stability. Simulation and experiment results have proved that the LCL-filter and the control strategy are valid, the system is stable and the use of LCL-filter has good compensation performance.

\section{REFERENCES}

[1] G. J. Jun, X. D. Guo, and L. H. Kui, "Active power filter technology and its development," in Proc. of Electric Machines and Control, vol. 7, pp. 126-132, 2003.

[2] M. Liserre, F. Blaabjerg, and S. Hansen, "Design and control of an LCL-filter-based three-phase active rectifier," IEEE Trans. on Industry Applications, vol. 41, no. 5, pp. 1281- 1291,2005

[3] H. Y. Qi, J. X. Jian, and Q. Arui, "Active damping control of three-phase rectifier with LCL-filter," Electric Power Automation Equipment, vol. 29, no. 2, pp. 26-28, 2009.

[4] G. X. Qiang, W. W. Yang, G. H. Rong, W. L. Qiao, and Z. Q. Lin, "Modelling and Stability Analysis of Direct Output Current Control for LCL Interfaced Grid-Connected Inverters," Trans. of China Electrotechnical Society, vol. 3, pp.102-109, 2010.

[5] P. W. Fei and L. X. Ming, "Active Damping Control of LCL Filter Based on Shunt Active Power Filter," Shanxi Electric Power, vol. 39, pp. 41-46, 2010.

[6] Z. L. Qiu, "The Study on Key Techniques of Three-Phase Three-Line Grid-Connected Converter Based on LCL-filter," Dept. Elect. Eng. Zhejiang Univ. 2008. 
[7] L. K. Deng, "Research on Harmonics Elimination and Reactive Power Compensation Applied to Three-Phase Four-wire System," M. S. thesis, Department of Electrical Engineering, Tsinghua University, 2005

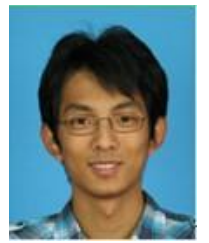

Longfei $\mathbf{L i}$ was born on October 20, 1988. He received the B. Eng. degree in electrical engineering from Beijing Jiaotong University, Beijing, China, in 2011.Now he is currently working toward the M.Sc. degree in the Department of Electrical Engineering in Tsinghua University, Beijing, China. Now he is working on the research of power quality in the power system.

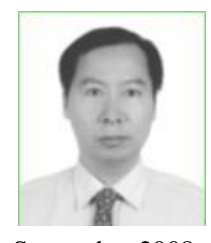

Xinjian Jiang was born on November 19, 1964. He received the B. Eng. degree in 1987 and M.S. degree from the Electrical Engineering Department of Tsinghua University, Beijing, China. Since 2000, he has been an Associate Professor at the Tsinghua University, Beijing, China. He worked at Aalborg University, Denmark as a visiting scholar from September 2008 to August 2009. His main area of interest is the control of power quality, motor drives and converter for wind turbines. 